\title{
O025. Excitability of the motor cortex in migraine changes with the distance from the last attack
}

\author{
Gianluca Coppola ${ }^{1 *}$, Francesca Napoli ${ }^{2}$, Davide Di Lenola², Martina Bracaglia², Mariano Serrao², \\ Cherubino Di Lorenzo ${ }^{3}$, Francesco Pierelli ${ }^{2}$ \\ From Abstracts from the 1st Joint ANIRCEF-SISC Congress \\ Rome, Italy. 29-31 October 2015
}

\section{Background}

Single-pulse transcranial magnetic stimulation studies of motor cortex have the advantage of relying on an objective measure, the motor evoked potential (MEP) recorded in peripheral muscles, to non-invasively explore the cortical excitability. Previously, thresholds for MEP were found to be normal, increased or even reduced in migraine. In the present study, we investigated whether the level of cortical excitability changes with the distance from the last migraine attack could explain these inconsistent results.

\section{Methods}

Twenty-six patients with untreated migraine without aura (MO) underwent MEP study between attacks and were compared to a group of 24 healthy volunteers (HV). The TMS figure-of-eight coil was positioned over the left motor area. We first identified the resting motor threshold (RMT) and then amplitude of MEP was evaluated by delivering and averaging 10 single pulses of TMS using a stimulus intensity of $120 \%$ RMT at a rate of $0.1 \mathrm{~Hz}$.

\section{Results}

Mean RMTs (54.2 in MO vs. 55.8 in HV) and MEP amplitudes ( $3057 \mathrm{~V}$ in MO vs. $3675 \mathrm{~V}$ in HV) were not significantly different between $\mathrm{MO}$ and $\mathrm{HV}$. In MO, the RMT negatively correlated with days elapsed since the last migraine attack $(\mathrm{r}=-0.426, \mathrm{p}=0.03)$.

\section{Conclusions}

From the present data emerges that the threshold for evoking MEP is influenced by the proximity of an attack since it is minimal at a long time interval after an attack,

\footnotetext{
* Correspondence: gianluca.coppola@gmail.com

'G.B. Bietti Foundation IRCCS, Department of Neurophysiology of Vision and Neuro-ophthalmology, Rome, Italy

Full list of author information is available at the end of the article
}

while it is greater and within the range of normative values approaching an attack. The dynamic RMT variations found here resemble those we had previously reported for visual and somatosensory evoked potentials, and may represent time-dependent plastic changes in brain excitability in relation with the migraine cycle.

Written informed consent to publish was obtained from the patient(s).

\section{Authors' details}

'G.B. Bietti Foundation IRCCS, Department of Neurophysiology of Vision and Neuro-ophthalmology, Rome, Italy. "Sapienza" University of Rome Polo Pontino, Department of Medico-Surgical Sciences and Biotechnologies, Latina, Italy. ${ }^{3}$ Don Carlo Gnocchi Onlus Foundation, Milan, Italy.

Published: 28 September 2015

doi:10.1186/1129-2377-16-S1-A158

Cite this article as: Coppola et al: O025. Excitability of the motor cortex in migraine changes with the distance from the last attack. The Journal of Headache and Pain 2015 16(Suppl 1):A158.

Submit your manuscript to a SpringerOpen ${ }^{\circ}$ journal and benefit from:

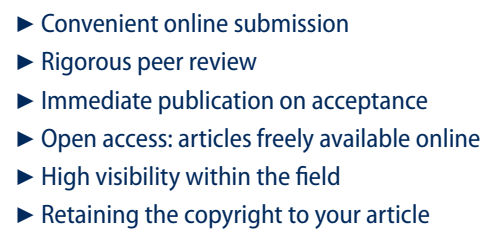

Submit your next manuscript at $\gg$ springeropen.com 